\title{
Vectra 3D (dinotefuran, pyriproxyfen and permethrin) prevents acquisition of Borrelia burgdorferi sensu stricto by Ixodes ricinus and Ixodes scapularis ticks in an ex vivo feeding model
}

Djamel Tahir ${ }^{1}$, Btissam Asri ${ }^{1,2}$, Leon Nicolaas Meyer ${ }^{1}$, Alec Evans ${ }^{1}$, Thomas Mather ${ }^{3}$, Byron Blagburn ${ }^{4}$, Reinhard K. Straubinger ${ }^{5}$, Valérie Choumet ${ }^{6}$, Frans Jongejan ${ }^{7}$ and Marie Varloud ${ }^{8^{*}}$ (1)

\begin{abstract}
Background: We evaluated the efficiency of an ex vivo feeding technique using a silicone membrane-based feeding chamber to (i) assess the anti-feeding and acaricidal efficacy of a spot-on combination of dinotefuran, pyriproxyfen and permethrin (DPP, Vectra ${ }^{\circledR} 3 \mathrm{D}$ ) against adult Ixodes scapularis and Ixodes ricinus ticks, and to (ii) explore its effect on blocking the acquisition of Borrelia burgdorferi sensu stricto.
\end{abstract}

Methods: Eight purpose-bred dogs were randomly allocated to two equal-size groups based on body weight assessed on day 2. DPP was administered topically, as spot-on, to four dogs on day 0 . Hair from the eight dogs was collected individually by brushing the whole body on days $2,7,14,21,28$ and 35 . On each day of hair collection, $0.05 \mathrm{~g}$ of sampled hair was applied on the membrane corresponding to each feeding unit (FU). Seventy-two FU were each seeded with 30 adults of I. scapularis ( $n=24 \mathrm{FU}$ ) or I. ricinus ticks ( $n=48 \mathrm{FU}$ ). Bovine blood spiked with B. burgdorferi sensu stricto (strain B31) was added into each unit and changed every $12 \mathrm{~h}$ for 4 days. Tick mortality was assessed $1 \mathrm{~h}$ after seeding. One additional hour of incubation was added for live/moribund specimens and reassessed for viability. All remaining live/moribund ticks were left in the feeders and tick engorgement status was recorded at $96 \mathrm{~h}$ after seeding, and the uptake of B. burgdorferi s.s. was examined in the collected ticks by applying quantitative real-time PCR.

Results: Exposure to DPP-treated hair was 100\% effective in blocking B. burgdorferi s.s. acquisition. The anti-feeding efficacy remained stable (100\%) against both /xodes species throughout the study. The acaricidal efficacy of DPP evaluated at 1 and $2 \mathrm{~h}$ after exposure was 100\% throughout the study for I. ricinus, except the 1-h assessment on day 28 (95.9\%) and day 35 (95.3\%). The 1-h assessment of acaricidal efficacy was 100\% at all time points for I. scapularis.

Conclusions: The ex vivo feeding system developed here demonstrated a protective effect of DPP against the acquisition of $B$. burgdorferi without exposing the animals to the vectors or to the pathogen.

*Correspondence: marie.varloud@ceva.com

${ }^{8}$ Ceva Santé Animale, 10 Avenue de la Ballastière, 33500 Libourne, France

Full list of author information is available at the end of the article permits use, sharing, adaptation, distribution and reproduction in any medium or format, as long as you give appropriate credit to the original author(s) and the source, provide a link to the Creative Commons licence, and indicate if changes were made. The images or other third party material in this article are included in the article's Creative Commons licence, unless indicated otherwise in a credit line to the material. If material is not included in the article's Creative Commons licence and your intended use is not permitted by statutory regulation or exceeds the permitted use, you will need to obtain permission directly from the copyright holder. To view a copy of this licence, visit http://creativecommons.org/licenses/by/4.0/. The Creative Commons Public Domain Dedication waiver (http://creativeco mmons.org/publicdomain/zero/1.0/) applies to the data made available in this article, unless otherwise stated in a credit line to the data. 
Keywords: Canine Lyme borreliosis, Ixodes scapularis, Ixodes ricinus, Borrelia burgdorferi, Blocking transmission, Prevention, Ex vivo model

\section{Background}

Ticks are obligate hematophagous ectoparasites that parasitize vertebrate animals (birds, mammals and reptiles) and occasionally attach to humans [1]. Within the Ixodidae family (also called hard ticks), Ixodes is the largest genus, containing 217 species [2]. Ixodid ticks transmit a larger variety of infectious agents, including viruses, bacteria (rickettsiae and spirochaetes), protozoa and helminths, than any other arthropod vector group, and are among the most important vectors of infections affecting livestock, companion animals and humans $[1,3,4]$.

Ticks in the genus Ixodes are most familiar as vectors of the Lyme disease (LD) spirochete (Borrelia burgdorferi). Ixodes ricinus, known as the sheep tick or castor bean tick, is the most abundant European tick species but it is also widespread in North Africa [5, 6]. On dogs, this tick species can act as a vector of many pathogens including Borrelia burgdorferi sensu lato, Anaplasma phagocytophilum and Babesia spp., which are the causative agents of Lyme borreliosis (LB), canine granulocytic anaplasmosis and babesiosis, respectively [6]. Within the North American Ixodes species, the blacklegged tick, Ixodes scapularis, is the most frequently incriminated vector for B. burgdorferi sensu stricto and A. phagocytophilum in dogs [7]. All stages of I. ricinus and I. scapularis can feed on dogs and bite humans, enabling the transmission of several pathogens to people including those causing LB, rickettsiosis, anaplasmosis, babesiosis, tick-borne encephalitis, Powassan virus disease and many more $[8,9]$. Immature $I$. scapularis, at least, also can acquire an infectious dose of the LD agent while feeding on dogs [10].

Preventing tick bites and thus the transmission of tickborne pathogens requires the use of molecules that target the tick and/or pathogen survival [11]. Protecting dogs from tick infestation is commonly achieved by periodic application of effective repellent and acaricidal agents. Nevertheless, the relevance of these chemical compounds in blocking pathogen transmission is related to the speed of transmission of the specific pathogen by its tick vector [12]. This time of transmission may vary between pathogens and is influenced by numerous variables. Some studies have shown that transmission can occur much faster than expected [13, 14]. Therefore, pharmaceutical compounds should be characterized by a fast onset of killing activity and/or repellence against arthropods [12].

Although vaccination offers an alternative approach for preventing tick-borne pathogen infections, currently the protective spectrum of vaccines is limited, and there are none available for most of the canine tick-borne diseases $[15,16]$.

Recently, several artificial feeding methods of ixodid ticks have been developed to study tick-host-pathogen interactions under laboratory conditions [17-22]. Artificial membrane feeding devices were successfully used to evaluate the killing efficacy of chemicals or biogenic compounds such as acaricides and antimicrobials used against hematophagous arthropods. For instance, Kröber and Guerin [23] demonstrated the possibility of using membrane feeding to evaluate the acaricidal effect of fipronil and ivermectin against female I. ricinus ticks feeding through a silicone membrane. Similarly, the effectiveness of ivermectin and doxycycline in killing body lice was assessed using a parafilm membrane and human blood as an in vitro system [24].

In this study, we investigated an ex vivo feeding model, wherein hair collected from dogs previously treated with Vectra 3D (dinotefuran, pyriproxyfen and permethrin) was introduced to assess its ability to prevent the acquisition of B. burgdorferi s.s. by I. ricinus and $I$. scapularis ticks.

\section{Methods \\ Dog study design}

Eight healthy purpose-bred Beagle dogs were clinically examined on day 7 for inclusion in the study. On day 2 , the dogs were randomly assigned to two groups (dinotefuran-permethrin-pyriproxyfen [DPP] or untreated control group) of four dogs each according to their body weight. The dogs were individually housed indoors at a temperature of $24{ }^{\circ} \mathrm{C}\left( \pm 3{ }^{\circ} \mathrm{C}\right)$. No physical contact was allowed between animals from the different groups. The dogs were fed a commercial dry food at the recommended rates and water ad libitum. General health observations were performed once daily for the duration of the study. On day 0, DPP was administered topically based on the manufacturer's instructions [25] as a line-on treatment along the length of the spine to four dogs $(1.6 \mathrm{ml} / \mathrm{dog}$ weighing between 5 and $10 \mathrm{~kg}$ and $3.6 \mathrm{ml} / \mathrm{dog}$ weighing between 10 and $25 \mathrm{~kg}$ ). Hair (about $3.2 \pm 1.8 \mathrm{~g} / \mathrm{dog}$ ) from the eight dogs was collected from each individual by brushing the whole body (using single-use brushes for DPP-treated dogs) over a period of about $10 \mathrm{~min}$, on days 2, 7, 14, 21, 28 and 35 (Fig. 1). 


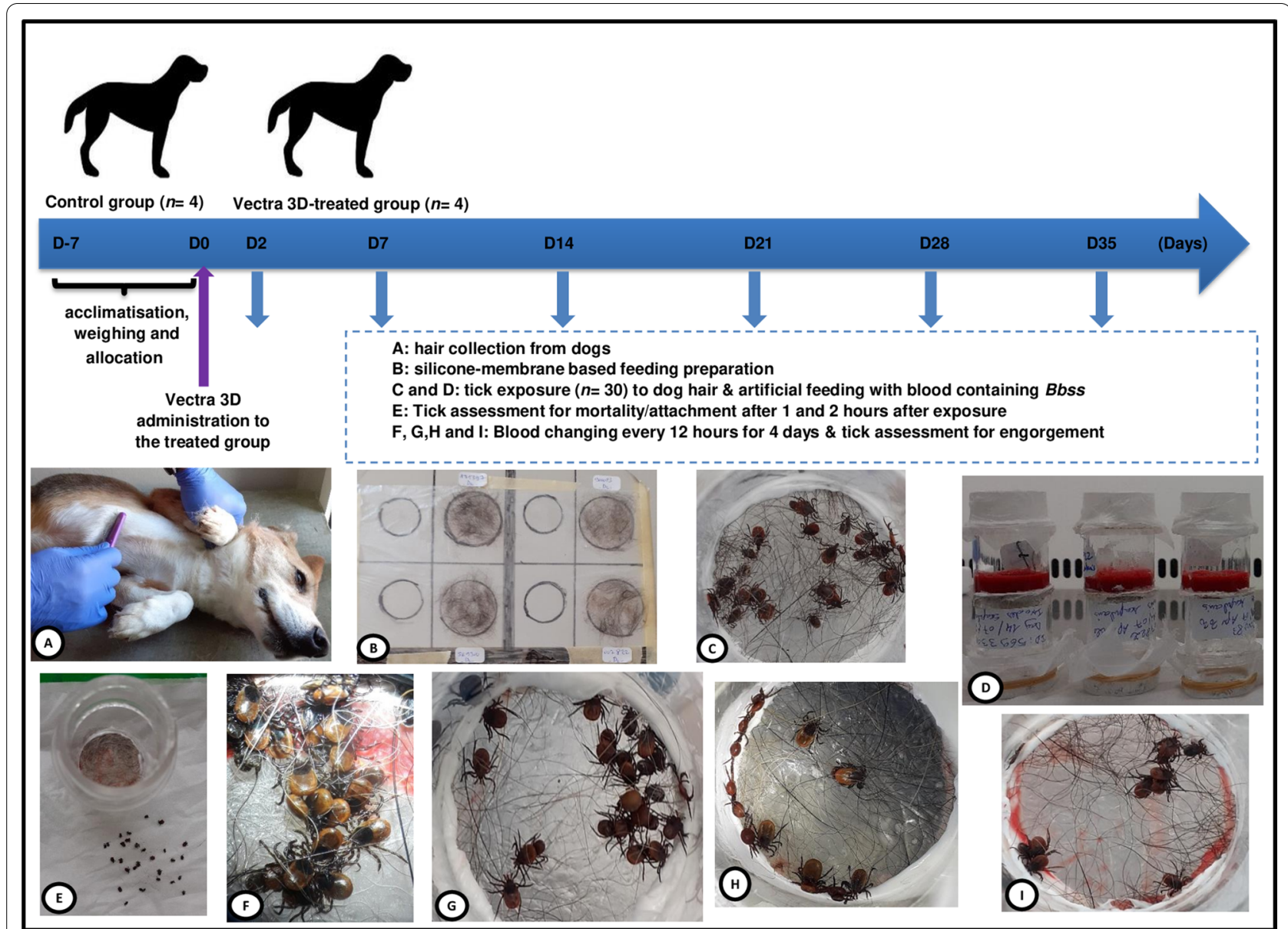

Fig. 1 Summary of the experiments conducted in this study. a Hair collection on a dog using an individual comb. b Preparation of silicone-based membrane. c Chamber 1 filled with 30 ticks. $\mathbf{d}$ Dead ticks assessed after $1 \mathrm{~h}$ of DPP-treated dog hair contact. e I. ricinus clustering on the artificial membrane 3 days after tick infestation. f Feeding units made from two plexiglass chambers, chambers 1 and 2, containing ticks and blood, respectively. $\mathbf{g}$ Feeding unit illustration: chamber 1 with organza tissue at the base to restrain ticks; chamber 2 containing blood with end covered with sterile parafilm; artificial membrane glued between chambers 1 and 2. $\mathbf{h}$ Cluster of semi-engorged adult I. scapularis ticks feeding on the artificial membrane. $\mathbf{i}, \mathbf{j}$ Partially engorged I. scapularis ticks after $84 \mathrm{~h}$ of feeding

Ticks

Adult female and male I. ricinus and I. scapularis (at the age of 6 to 8 weeks after molting) were obtained from Clinvet's colony initiated in 2012 using adult specimens from Georgia (USA) and Utrecht (the Netherlands), respectively, collected in the field by F. Jongejan. Pathogen-free ticks were maintained by routine passage on rabbits for larvae and nymphs, and on sheep for adult ticks. Prior to use in the study, ticks were maintained at $10-12{ }^{\circ} \mathrm{C}$ and relative humidity (RH) of $85-95 \%$ (Panasonic Corporation, Osaka, Japan). To increase their willingness to feed, ticks were transferred to $22{ }^{\circ} \mathrm{C}, 90 \%$ $\mathrm{RH}$ and 16:8 h light/dark photoperiod at least 5 days prior to tick feeding challenges.

\section{Bacterial strain}

The B. burgdorferi sensu stricto strain B31 (Bbss; ATCC 35210; American Type Culture Collection, Manassas, VA 20110 USA) was used in this experiment. Borrelia cultures were maintained in complete Barbour-StoennerKelly medium (BSK-H) at $34{ }^{\circ} \mathrm{C}$ as described previously [26]. The spirochete cell viability and concentration were determined by counting spirochetes in defined suspension volumes using a dark-field microscope.

\section{Membrane and tick feeding chamber preparation}

The feeding unit (FU) design was prepared based on a method described previously [23, 27]. Briefly, the feeding units were made by two plexiglass tubing chambers stacked on each other (Fig. 1). Chamber 1 (containing 
ticks) was separated from chamber 2 (containing blood) by a previously prepared silicone-based membrane which was gently fixed to the feeding chamber using mastic silicone glue (SikaSeal ${ }^{\circledR}$, Ballymun, Ireland). Feeding membranes consisted of goldbeater's skin originally made from bovine intestine (Preservation Equipment Ltd, Norfolk, UK) with a thickness of $30 \mu \mathrm{m}$, which were treated with a thin layer of silicone rubber (Smooth-On, Inc., East Texas, PA) mixture to improve the softness, resulting in a final membrane thickness of $100-140 \mu \mathrm{m}$. The silicone mixture was prepared as reported previously [27]. Just after adding the silicone mixture, $0.05 \mathrm{~g}$ of dog hair (DPP-treated or non-treated control) was added to the membrane in the circle corresponding to the placement of the feeding chamber (Fig. 1). The membrane was allowed to polymerize overnight at room temperature.

\section{Preparation of blood seeded with Bbss}

Blood was collected weekly from Borrelia-free cattle (Clinvet's facility) in $500 \mathrm{ml}$ sterile collection bags supplemented with citrate (MacoPharma, Mouvaux, France). The blood was supplemented with glucose (SigmaAldrich, St. Louis, MO, USA) to a concentration of $2 \mathrm{~g} / \mathrm{l}$ and stored at $4{ }^{\circ} \mathrm{C}$. Prior to blood replacement, the required volume of blood was warmed to $37{ }^{\circ} \mathrm{C}$. Blood was then spiked with BSK-H medium containing spirochetes to obtain a final concentration of $10^{4} \mathrm{Bbss}$ cells $/ \mathrm{ml}$. The blood was changed every $12 \mathrm{~h}$ for 4 days, and during this process, all chambers containing blood (chamber 2) were rinsed at least twice with warm $0.9 \% \mathrm{NaCl}$ containing gentamicin $(10 \mathrm{mg} / \mathrm{ml}$; Sigma-Aldrich) and then left to dry for 5 min under a biosafety cabinet.

\section{Tick seeding, incubation, mortality and engorgement assessment}

Each FU was filled with 30 adult ticks (1:1 sex ratio) of I. ricinus on days $2,7,14,21,28$ and 35 or I. scapularis on days 2,14 and 28 . The availability of $I$. scapularis did not allow for testing at every time point. Three milliliters of prepared bovine blood containing Bbss was added into each FU and then sealed with sterile parafilm (Fig. 1).

FU were incubated at $37{ }^{\circ} \mathrm{C}$ with humidity $>85 \%$. Tick mortality was assessed $1 \mathrm{~h}$ after exposure to the hair. However, one additional hour of incubation was added to determine the survival of the live and/or moribund specimens. The engorgement status of all remaining live ticks was assessed after 4 days of incubation. Ticks were categorized with the naked eye as semi-engorged or non-engorged. However, a stereomicroscope was used to detect traces of a blood meal when differentiation was not possible with the naked eye.
It should be noted that wherever possible, the guidelines for evaluating the efficacy of parasiticides in reducing vector-borne pathogen transmission, recently published by the World Association for the Advancement of Veterinary Parasitology (WAAVP) were properly followed [29].

\section{DNA isolation and qPCR screening of the ticks}

After each collection time point, ticks were washed twice in phosphate-buffered saline (PBS, Sigma-Aldrich) and dried. Ticks were then labeled and stored at $-20^{\circ} \mathrm{C}$ until DNA extraction. DNA was extracted from whole ticks using a NucleoSpin tissue kit according to the manufacturer's recommendations (Macherey-Nagel, Hoerdt, France). For the non-treated group, DNA was extracted from all semi-engorged females, while for the treated group, three specimens per feeder per time point were randomly selected and DNA was individually extracted. In addition, nine attached males classified as semiengorged were tested for $B b s s$. The uptake of $B b s s$ organisms was examined by quantitative real-time polymerase chain reaction (qPCR), as described previously [30]. Individual ticks were processed separately, and spirochete acquisition was considered successful when the number of threshold cycles $(\mathrm{Ct})$ was $<36$. Negative controls were processed with DNA-free water and DNA from uninfected ticks, and the positive control was genomic DNA of $B b s s$.

\section{Efficacy assessment and statistical analysis}

Live tick counts (attached or free and engorged or nonengorged) were transformed to the natural logarithm of (count +1$)$ to calculate the geometric means $(\mathrm{GM})$ at each time point for both Ixodes tick species. The efficacy was calculated using Abbott's formula (Abbott 1987):

Acaricidal efficacy $(\%)=100 \times \frac{\mathrm{MC}-\mathrm{MT}}{\mathrm{MC}}$, where $\mathrm{MC}$ is the GM of live ticks in the control group (group 1), and MT is the GM of live ticks in the treated group.

Antifeeding efficacy $(\%)=100 \times \frac{\mathrm{MC}-\mathrm{MT}}{\mathrm{MC}}$, where MC is the GM of engorged ticks in the control group and MT is the GM of engorged ticks in the treated group.

The percentage effectiveness of DPP in preventing $B b s s$ acquisition by ticks was calculated as follows:

Efficacy $(\%)=100 \times \frac{\mathrm{PC}-\mathrm{PT}}{\mathrm{PC}}$, where $\mathrm{PC}$ is the percentage of ticks positive for $B b s s$ based on qPCR in the untreated control group and PT is the percentage of positive ticks in the treated group.

Data were analyzed using Excel to calculate the GM and standard deviation. Statistical analyses were performed using GraphPad Prism 6 software (https:// www.graphpad.com/). At each time point, differences between treated and untreated groups were compared using the non-parametric two-tailed Mann-Whitney $U$ 
test. Pearson's $\chi^{2}$ test was performed for analysis of the engorgement rates between the two species, and Fisher's exact test was used to evaluate the differences in the prevalence of spirochete acquisition. Values of $p<0.05$ were considered statistically significant.

\section{Results}

All treated dogs tolerated the DPP administration, with no abnormal signs occurring throughout the study. In the non-treated group, both tick species exhibited normal behavior when exposed to dog hair in the feeding chamber, and tick attachment was observed during the first $2 \mathrm{~h}$ of release into the chamber. There was no tick mortality recorded in this group for either species during the first hours of assessment ( 1 and $2 \mathrm{~h}$ of incubation), yielding a GM of 30 live ticks (Table 1). At each subsequent challenge, some non-attached ticks were found dead, particularly between 2 and 4 days of incubation, but this mortality did not exceed $12 \%$ (Table 1 ).

In the untreated control group, ticks successfully attached and fed through the artificial feeding membrane, with engorgement values (recorded after $96 \mathrm{~h}$ of incubation) ranging from 20.0 to $36.7 \%$ (27.7 $\pm 1.9 \%)$ for $I$. ricinus and from 36.6 to $41.6 \%(39.4 \pm 1.9 \%)$ for $I$. scapularis (Table 3). Female I. scapularis fed better than female $I$. ricinus, with a statistically significant difference $\left(X^{2}=7.54, p=0.006\right)$. We occasionally observed attached and slightly engorged males (Fig. 2), with a total of nine males categorized as semi-engorged. The GM of semi-engorged ticks ranged from 3.3 to 6.4 and from 6.7 to 7.2 for I. ricinus and I. scapularis, respectively (Table 2). It should be noted that only female ticks were considered in this assessment (each feeder contained 15 females) (Table 3). Bbss DNA was detected in a total of
96\% (96/100) and $95.7 \%(68 / 71)$ of partially engorged female $I$. ricinus and $I$. scapularis, respectively (Table 4). A total of eight partially engorged males (I. scapularis: $n=6 / 7$ and I. ricinus: $n=2 / 2$ ) were tested positive for $B$. burgdorferi.

In the DPP-treatment group, the ticks exhibited signs of intoxication, such as agitation, then uncoordinated movements and "hot-foot"-like behavior after only 15 min of contact with the DPP-treated hair. The proportion of dead $I$. ricinus assessed after $1 \mathrm{~h}$ of incubation was $100 \%(\mathrm{GM}=30)$ during the first four challenges (days 2, 7, 14 and 21), which decreased slightly to $95 \%$ $(\mathrm{GM}=28.5)$ and $94 \%(\mathrm{GM}=28.2)$ on days 28 and 35 , respectively (Table 1 ). The 2 -h mortality for this tick species was $100 \%$ for each of the time points (Table 1). For $I$. scapularis, $100 \%(\mathrm{GM}=30)$ mortality was noted at each time point during the first $1 \mathrm{~h}$ of incubation (Table 1 ). The immediate 1 - $\mathrm{h}$ acaricidal efficacy of DPP-treated hair against $I$. ricinus ticks remained above $95 \%$ and reached $100 \%$ at the 2 -h counts (Table 3 ). This efficacy was $100 \%$ at $1 \mathrm{~h}$ for I. scapularis at each time point (Table 3). For both tick species, there was a significant difference between the treated and control groups ( $U$ test, $p$ value varied between 0.006 and 0.01 ) in the number of dead ticks found at 1 and $2 \mathrm{~h}$ of incubation.

No attachment was observed in the DPP-treated group. DPP had 100\% anti-feeding effect against both tick species throughout the study (Table 2). At each time point, the difference in the engorgement mean of female $I$. ricinus and $I$. scapularis between the treated and control groups was significant $(p<0.001)$.

All of the randomly selected female ticks from the DPP-treated group (I. ricinus: $n=72$ and I. scapularis: $n=36$ ) tested negative for B. burgdorferi DNA (Table 4).

Table 1 Mortality assessment of adult Ixodes ricinus and Ixodes scapularis ticks exposed for 1 and 2 h to dog hair treated with dinotefuran-permethrin-pyriproxyfen or not treated

\begin{tabular}{|c|c|c|c|c|c|c|c|c|c|}
\hline \multirow{4}{*}{$\begin{array}{l}\text { Day of } \\
\text { exposure }\end{array}$} & \multicolumn{6}{|c|}{ Ixodes ricinus } & \multirow{2}{*}{\multicolumn{3}{|c|}{$\frac{\text { Ixodes scapularis }}{1 \mathrm{~h}}$}} \\
\hline & \multicolumn{3}{|l|}{$1 \mathrm{~h}$} & \multicolumn{3}{|l|}{$2 \mathrm{~h}$} & & & \\
\hline & \multirow{2}{*}{$\begin{array}{l}\text { Non- } \\
\text { treated } \\
\text { control }\end{array}$} & \multicolumn{2}{|l|}{ DPP-treated group } & \multirow{2}{*}{$\begin{array}{l}\text { Non- } \\
\text { treated } \\
\text { control }\end{array}$} & \multicolumn{2}{|l|}{ DPP-treated group } & \multirow{2}{*}{$\begin{array}{l}\text { Non- } \\
\text { treated } \\
\text { control }\end{array}$} & \multicolumn{2}{|l|}{ DPP-treated group } \\
\hline & & Dead tick count (\%) & $\begin{array}{l}\text { Mean tick } \\
\text { count } \pm S D\end{array}$ & & Dead tick count (\%) & $\begin{array}{l}\text { Mean } \\
\text { tick } \\
\text { count }\end{array}$ & & Dead tick count (\%) & $\begin{array}{l}\text { Mean } \\
\text { tick } \\
\text { count }\end{array}$ \\
\hline 2 & 0 & $120(100)$ & $30 \pm 0$ & 0 & $120(100)$ & 30 & 0 & $120(100)$ & 30 \\
\hline 7 & 0 & $120(100)$ & $30 \pm 0$ & 0 & $120(100)$ & 30 & $\mathrm{~N} / \mathrm{A}$ & $\mathrm{N} / \mathrm{A}$ & $\mathrm{N} / \mathrm{A}$ \\
\hline 14 & 0 & $120(100)$ & $30 \pm 0$ & 0 & $120(100)$ & 30 & 0 & $120(100)$ & 30 \\
\hline 21 & 0 & $120(100)$ & $30 \pm 0$ & 0 & $120(100)$ & 30 & $\mathrm{~N} / \mathrm{A}$ & $\mathrm{N} / \mathrm{A}$ & $\mathrm{N} / \mathrm{A}$ \\
\hline 28 & 0 & $114(95.0)$ & $28.5 \pm 1.9$ & 0 & $120(100)$ & 30 & 0 & $120(100)$ & 30 \\
\hline 35 & 0 & $113(94.1)$ & $28.2 \pm 1.2$ & 0 & $120(100)$ & 30 & N/A & N/A & $\mathrm{N} / \mathrm{A}$ \\
\hline
\end{tabular}

SD standard deviation, / no experiment conducted for /xodes scapularis due to limited tick availability 


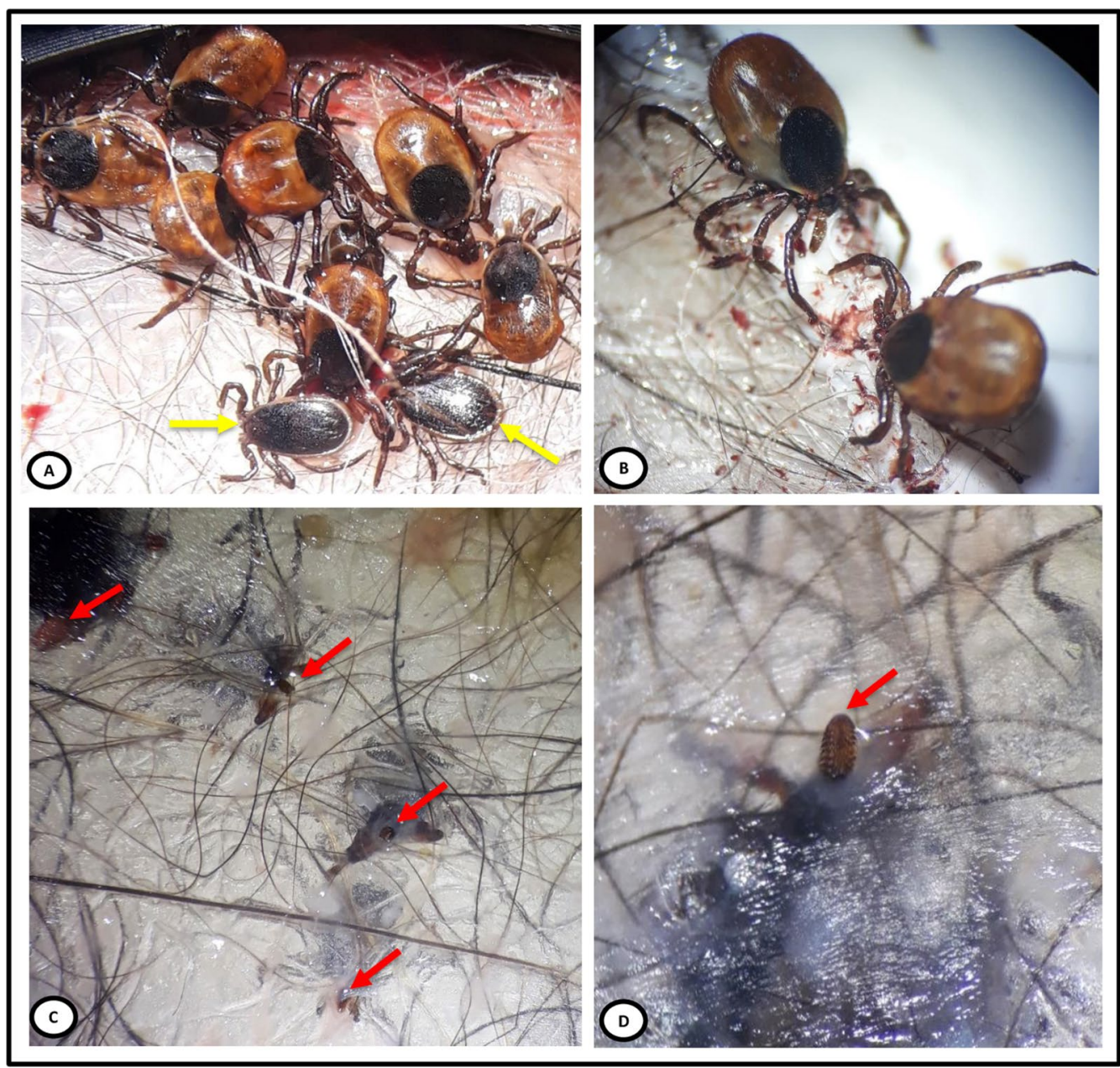

Fig. 2 Engorgement status of adult /xodes ticks on the silicone membrane following 4 days of tick feeding. a Group of partially engorged I. scapularis females; example of males considered attached and semi-engorged are indicated with yellow arrows. b Semi-engorged females I. ricinus. c, $\mathbf{d}$ Outside view of the adult tick hypostomes perforating the silicone membrane, indicated with red arrows

Table 2 Anti-feeding efficacy of DPP-treated dog hair against Ixodes ricinus and Ixodes scapularis ticks

\begin{tabular}{|c|c|c|c|c|c|c|c|c|}
\hline \multirow{3}{*}{$\begin{array}{l}\text { Day of } \\
\text { exposure }\end{array}$} & \multicolumn{4}{|l|}{ Ixodes ricinus ${ }^{\mathrm{a}}$} & \multicolumn{4}{|l|}{ Ixodes scapularis ${ }^{a}$} \\
\hline & \multirow{2}{*}{$\begin{array}{l}\text { Total number of fed ticks } \\
\text { (\%) in non-treated control } \\
\text { groups }\end{array}$} & \multicolumn{2}{|c|}{$\begin{array}{l}\text { GM number of fed } \\
\text { ticks } \pm S D\end{array}$} & \multirow[t]{2}{*}{$\begin{array}{l}\text { Anti-feeding } \\
\text { efficacy (\%) }\end{array}$} & \multirow{2}{*}{$\begin{array}{l}\text { Total number of fed ticks } \\
\text { (\%) in non-treated control } \\
\text { groups }\end{array}$} & \multicolumn{2}{|c|}{$\begin{array}{l}\text { GM number of fed } \\
\text { ticks } \pm S D\end{array}$} & \multirow{2}{*}{$\begin{array}{l}\text { Anti- } \\
\text { feeding } \\
\text { efficacy } \\
(\%)\end{array}$} \\
\hline & & $\begin{array}{l}\text { Non-treated } \\
\text { control } \\
\text { groups }\end{array}$ & $\begin{array}{l}\text { DPP- } \\
\text { treated } \\
\text { groups }\end{array}$ & & & $\begin{array}{l}\text { Non-treated } \\
\text { control } \\
\text { groups }\end{array}$ & $\begin{array}{l}\text { DPP- } \\
\text { treated } \\
\text { groups }\end{array}$ & \\
\hline 2 & $22(36.7)$ & $6.4 \pm 1.3$ & 0 & 100 & $24(40.3)$ & $6.7 \pm 2.4$ & 0 & 100 \\
\hline 7 & $17(28.3)$ & $5.2 \pm 0.9$ & 0 & 100 & & N/A & N/A & N/A \\
\hline 14 & $18(30.0)$ & $5.4 \pm 1.3$ & 0 & 100 & $22(36.7)$ & $5.9 \pm 3.1$ & 0 & 100 \\
\hline 21 & $15(25.0)$ & $4.7 \pm 0.9$ & 0 & 100 & & N/A & N/A & N/A \\
\hline 28 & $12(20.0)$ & $3.3 \pm 2.1$ & 0 & 100 & 25 (41.6) & $7.2 \pm 1.0$ & 0 & 100 \\
\hline 35 & $16(26.7)$ & $4.9 \pm 0.8$ & 0 & 100 & & N/A & N/A & N/A \\
\hline
\end{tabular}

anly females were considered during the assessment. Each feeding chamber contained 15 female ticks

GM geometric mean, SD standard deviation, / = no experiment conducted for /xodes scapularis due to limited tick availability 
Table 3 Acaricidal efficacy of DPP-treated dog hair against Ixodes ricinus and Ixodes scapularis ticks

\begin{tabular}{|c|c|c|c|c|c|c|c|c|c|}
\hline \multirow{4}{*}{$\begin{array}{l}\text { Day of } \\
\text { exposure }\end{array}$} & \multicolumn{6}{|l|}{ Ixodes ricinus } & \multicolumn{3}{|c|}{ Ixodes scapularis } \\
\hline & \multicolumn{4}{|c|}{ GM number of alive ticks } & \multicolumn{2}{|c|}{$\begin{array}{l}\text { Acaricidal efficacy } \\
(\%)\end{array}$} & \multirow{2}{*}{\multicolumn{2}{|c|}{$\begin{array}{l}\text { GM number of alive ticks } \\
1 \mathrm{~h}\end{array}$}} & \multirow{3}{*}{$\begin{array}{l}\text { Acaricidal } \\
\text { efficacy } \\
(\%) \\
1 \mathrm{~h}\end{array}$} \\
\hline & \multicolumn{2}{|l|}{$1 \mathrm{~h}$} & \multicolumn{2}{|l|}{$2 \mathrm{~h}$} & \multirow[t]{2}{*}{$1 \mathrm{~h}$} & \multirow[t]{2}{*}{$2 \mathrm{~h}$} & & & \\
\hline & $\begin{array}{l}\text { Non-treated } \\
\text { controls }\end{array}$ & $\begin{array}{l}\text { DPP-treated } \\
\text { group }\end{array}$ & $\begin{array}{l}\text { Non-treated } \\
\text { controls }\end{array}$ & $\begin{array}{l}\text { DPP-treated } \\
\text { group }\end{array}$ & & & $\begin{array}{l}\text { Non-treated } \\
\text { controls }\end{array}$ & $\begin{array}{l}\text { DPP-treated } \\
\text { group }\end{array}$ & \\
\hline 2 & 30 & 0 & 30 & 0 & 100 & 100 & 30 & 0 & 100 \\
\hline 7 & 30 & 0 & 30 & 0 & 100 & 100 & N/A & N/A & N/A \\
\hline 14 & 30 & 0 & 30 & 0 & 100 & 100 & 30 & 0 & 100 \\
\hline 21 & 30 & 0 & 30 & 0 & 100 & 100 & N/A & N/A & N/A \\
\hline 28 & 30 & 0.97 & 30 & 0 & 96.9 & 100 & 30 & 0 & 100 \\
\hline 35 & 30 & 1.45 & 30 & 0 & 95.3 & 100 & N/A & N/A & N/A \\
\hline
\end{tabular}

/ no experiment conducted for Ixodes scapularis due to limited tick availability

Table 4 Preventive effect provided by DPP-treated dog hair against the acquisition of Bbss by Ixodes ricinus and Ixodes scapularis ticks

\begin{tabular}{|c|c|c|c|c|c|c|}
\hline \multirow[t]{3}{*}{ Day of exposure } & \multicolumn{3}{|l|}{ Ixodes ricinus ${ }^{\mathrm{a}}$} & \multicolumn{3}{|l|}{ Ixodes scapularis ${ }^{\mathrm{a}}$} \\
\hline & \multicolumn{2}{|c|}{ Total number of tested/positive ticks (\%) } & \multirow[t]{2}{*}{ Efficacy (\%) } & \multicolumn{2}{|c|}{ Total number of tested/positive ticks (\%) } & \multirow[t]{2}{*}{ Efficacy (\%) } \\
\hline & $\begin{array}{l}\text { Non-treated control } \\
\text { groups }\end{array}$ & $\begin{array}{l}\text { DPP-treated } \\
\text { groups }\end{array}$ & & $\begin{array}{l}\text { Non-treated control } \\
\text { groups }\end{array}$ & DPP-treated groups & \\
\hline 2 & $22 / 22(100)$ & $0 / 12(0)$ & 100 & $21 / 24(87.5)$ & $0 / 12(0)$ & 100 \\
\hline 7 & $17 / 17(100)$ & $0 / 12(0)$ & 100 & N/A & N/A & N/A \\
\hline 14 & 18/18 (100) & $0 / 12(0)$ & 100 & $22 / 22(100)$ & $0 / 12(0)$ & 100 \\
\hline 21 & $14 / 15(93.3)$ & $0 / 12(0)$ & 100 & N/A & N/A & N/A \\
\hline 28 & 10/12 (83.3) & $0 / 12(0)$ & 100 & $25 / 25(100)$ & $0 / 12(0)$ & 100 \\
\hline 35 & $15 / 16(93.7)$ & $0 / 12(0)$ & 100 & N/A & N/A & N/A \\
\hline
\end{tabular}

${ }^{a}$ Only females were considered during the assessment, / no experiment conducted for Ixodes scapularis due to limited tick availability

Thus, the preventive effect provided by DPP-treated dog hair against the acquisition of Bbss by I. ricinus and I. scapularis was $100 \%$ throughout the study period ( 35 and 28 days for I. ricinus and I. scapularis, respectively). For both tick species, there was a significant difference in the expected proportion of positive ticks between the control and the DPP-treated groups on Fisher's exact test $(p<0.00001)$.

\section{Discussion}

The ex vivo membrane-based feeding system developed here was successfully adapted to test the efficacy of Vectra 3D treatment of dog hair in preventing B. burgdorferi acquisition by adult $I$. ricinus and I. scapularis ticks over a period of 4 weeks. The $100 \%$ blocking efficacy reached at each time point was attributable to both the anti-feeding efficacy and the fast acaricidal effect against ticks observed during the first hours of exposure to treated hairs.
Efficacy assessment of veterinary products with acaricidal properties is usually performed on the target animal (e.g. cattle, cats, dogs, rabbits). Indeed, in experiments focusing on the transmission of vector-borne diseases, the animals are exposed not only to the bites of the vectors, but also to the infection by the pathogens they transmit $[31,32]$. In vivo procedures are stressful and painful for animals due to often massive tick bite burden as well as infection if the ticks are infected. In the case of LB studies, the pre-patent period required to rule out previous infection and the holding time, typically 4-6 weeks after infection, before serology can turn positive means that animals are on study for a lengthy time period. The goal of the 3R principles (replace, reduce and refine) is to always replace animal experiments whenever possible, reduce the number of animal experiments to the lowest possible, and ensure that the distress inflicted upon the animals is as low as possible. Alternative and more rapid methods for achieving the same study objectives while also reducing animal exposure and manipulation are thus 
desirable. In this study, we demonstrated the utility of an ex vivo artificial blood feeding assay system for assessing the efficacy of a quick tick knockdown product in preventing tick biting and feeding but where more than $80 \%$ of the activities previously performed on the dog, such as sedation, tick infestation and tick counts, were avoided.

In the current ex vivo assay, application of dog hair on the membrane as a chemical and mechanical stimulus appears to be an important factor in producing a satisfactory rate of tick attachment and engorgement (median engorgement rate of 27.8 and $39.4 \%$ for $I$. ricinus and $I$. scapularis, respectively) after only 4 days of tick incubation. In previous studies, bovine hair, sheep wool and deer hair extracts were applied to membranes to enhance attachment of immature and adult ixodid ticks fed in vitro $[21,28,33]$. In addition to the chemical stimulus, Kröber and Guerin [23] placed plastic crosses (2-mmthick tile spacer) on the membrane to create additional borders where ticks prefer to attach. In nature, attachment of ticks at feeding sites on the host also depends on an appropriate array of chemical and physical stimuli [34], where hair likely plays a key role.

In the present study, the number of ticks attached on the membranes was not recorded at each blood replacement, because it was not actually feasible to categorize them as attached or not without checking them individually using tweezers, which can disrupt the tick attachment process. In their study, Kröber and Guerin reported a $77 \%$ attachment rate by female I. ricinus, but only $54 \%$ of these females were still alive and feeding after 9 days of incubation. By comparison, the engorgement rate for I. ricinus reported here was lower (27.7\%), and this could be due to several parameters including the shorter period (4 days) ticks were allowed to feed and considering the possibility that some ticks may attach at a later time. When infestation is performed on target animals, the WAAVP recommend leaving ticks on the animals until completely engorged. As for I. scapularis, the median engorgement rate obtained in the present study was $39.4 \%$, which was close $(33-50 \%)$ to the frequency reported by Oliver et al. [35] when ticks were given 7 days of access to feed on an artificial membrane. Despite experiencing the same experimental conditions, the engorgement rate for I. scapularis (39.4\%) was significantly greater $(p=0.006)$ than that for I. ricinus $(27.7 \%)$. We observed that I. scapularis ticks appeared more active than I. ricinus, which may explain the difference in the engorgement rate.

Even though it is usually considered that adult male ticks of the genus Ixodes do not require a blood meal for spermiogenesis [36], in this study a number of male $I$. ricinus and $I$. scapularis males were occasionally observed to be attached directly on the membrane.
When their engorgement status was assessed with a stereomicroscope, a total of 9/540 specimens were classified as semi-engorged. To the best of our knowledge, only one study involving artificial feeding of Ixodes spp. ticks has reported the occurrence of blood feeding by males; in that study, $11 \%$ of feeders containing only $I$. ricinus males were found with the presence of feces inside [37]. In the present study, detection of $B$. burgdorferi DNA in eight male ticks suggests that adult Ixodes males may be capable of acquiring this bacterium during blood feeding. This hypothesis deserves to be investigated by both in vitro and in vivo studies using male Ixodes spp. ticks. Male Rhipicephalus sanguineus sensu lato, Dermacentor andersoni and Dermacentor reticulatus can take blood feeding on the host, and can both acquire and transmit pathogens in the absence of female ticks [13, 37-39].

Following a topical application of Vectra 3D, the three active substances (dinotefuran, permethrin and pyriproxyfen) were shown to be rapidly distributed over the body surface of the animal within the first day, with maximum concentrations on the hairs obtained 3 days after the application [26]. All three active substances were still detected in different zones of the hair coat 1 month after treatment [25]. The anti-feeding and acaricidal efficacy of DPP against adult I. ricinus [40] and I. scapularis [41] was already shown to persist on dogs for 1 month. The 24-h mortality assessed ex vivo against nymphal $I$. scapularis was $100 \%$ at all time points except on days $10(97.9 \%)$ and 17 (96.5\%) [42]. Interestingly, this formulation demonstrated remarkable speed of kill of both Ixodes tick species tested here. We know of no other product used for dogs as an acaricide that claims $100 \%$ effectiveness in just 1 to $2 \mathrm{~h}$ of tick contact with treated hair/animal for the entire month. This speed of kill action against $I$. ricinus and $I$. scapularis ticks is explained by the presence of permethrin (36.08\%). Permethrin is known to be a fastacting acaricide; it acts after contact with the arthropod and absorption into the arthropod either directly through the outer cuticle or through ingestion during feeding on the host $[43,44]$. The lipophilic properties of permethrin promote its distribution along the arthropod nervous system. Permethrin, like all pyrethroids, acts as a neurotoxin on voltage-gated sodium channels by slowing their activation and inactivation properties, leading to hyperexcitability and death [45]. In addition to its acaricidal effects, permethrin exerts a potent repellent and knockdown effect against numerous arthropods including ticks, and the primary repellent activity of pyrethroids is via contact irritancy [44]. This property is a key factor for the prevention of tick attachment on the host, which could explain why in the feeders containing DPP-treated hair, none of I. ricinus and I. scapularis scored positive. 
In this study, DPP completely prevented acquisition of $B$. burgdorferi by I. ricinus and I. scapularis ticks at each time point throughout the 1-month period following product administration. While not tested here, we might expect similar results if the experiment had used infected ticks and uninfected blood, since the transmission blocking effect is obtained through anti-feeding and acaricidal action on the vectors. Ixodes ricinus and I. scapularis ticks are mainly incriminated in the transmission of B. burgdorferi s.l., agent of LD. During a blood meal on the host, infected ticks release a small number of microorganisms into the skin. In general, inoculation of an infectious dose of bacteria by the tick bite occurs after 24-48 h [46]. However, for certain Borrelia strains (e.g., Bbss strain BRE 13), it has been observed that the transmission may occur within the first $12 \mathrm{~h} \mathrm{[14]}$. Therefore, to be effective in preventing transmission of tick-borne pathogens to pets, the most effective preventive products should prevent blood-feeding.

\section{Conclusions}

This study demonstrated a successful blocking effect of DPP against transmission of Borrelia bacteria, using an ex vivo artificial blood feeding chamber. A $100 \%$ acaricidal effect was achieved within 1-2 h after I. ricinus and $I$. scapularis ticks were in contact with DPP-treated hair, preventing tick attachment and engorgement. A single administration of DPP to dogs blocked transmission of Borrelia for up to 5 weeks due to strong anti-feeding and acaricidal efficacy against ticks.

\section{Abbreviations \\ Bbss: Borrelia burgdorferi sensu stricto; Bbsl: Borrelia burgdorferi sensu lato; LB: Lyme borreliosis; FU: Feeding units; DPP: Dinotefuran, pyriproxyfen and permethrin; GM: Geometric mean; RH: Relative humidity.}

\section{Acknowledgements}

We thank M. El Khobzi for his technical assistance.

\section{Authors' contributions}

DT, AE and MV designed the study and interpreted the results. LM, FJ, TM, VC $\mathrm{BB}$ and RKS contributed to the study design, result interpretation and validation. DT and BA performed the experiments. DT drafted the manuscript. All authors read and approved the final manuscript.

\section{Funding}

This study was funded by Ceva Santé Animale, 10 Avenue de la Ballastière, 33500 Libourne, 139 France. MV is an employee of Ceva Santé Animale.

\section{Availability of data and materials}

Data supporting the conclusions of this article are included within the article and its additional file. Further data of interest will be available from the corresponding author upon request.

\section{Declarations}

\section{Ethics approval and consent to participate}

The use of dogs as well as bovine blood was approved by the Clinvet Institutional Animal Care and Use Committee, South Africa, registration No. MDM-001-20.

\section{Consent for publication}

Not applicable.

\section{Competing interests}

Marie Varloud is an employee of Ceva Santé Animale. The other authors declare that they have no competing interests.

\section{Author details}

${ }^{1}$ Clinvet Morocco, B.P 301, 28815 Mohammedia, Morocco. ${ }^{2}$ Institut Agronomique Et Vétérinaire Hassan II, Rabat, Morocco. ${ }^{3}$ Center for Vector-Borne Disease, University of Rhode Island, Kingston, RI, USA. ${ }^{4}$ College of Veterinary Medicine, Auburn University, Auburn, AL 36849, USA. Institute for Infectious Diseases and Zoonoses, Bacteriology and Mycology, Faculty of Veterinary Medicine, Ludwig-Maximilians-University Munich, 80539 Munich, Germany. ${ }^{6}$ Environnement Et Risques Infectieux, Institut Pasteur, Paris, France. ${ }^{7}$ Vectors and Vector-Borne Diseases Research Programme, Department of Veterinary Tropical Diseases, Faculty of Veterinary Science, University of Pretoria, Onderstepoort, South Africa. ${ }^{8} \mathrm{Ceva}$ Santé Animale, 10 Avenue de la Ballastière, 33500 Libourne, France.

Received: 12 March 2021 Accepted: 19 July 2021

Published online: 21 August 2021

\section{References}

1. Parola P. Tick-borne rickettsial diseases: emerging risks in Europe. Comp Immunol Microbiol Infect Dis. 2004;27:297-304.

2. Nava S, Guglielmone AA, Mangold AJ. An overview of systematics and evolution of ticks. Front Biosci. 2009;14:2857-77.

3. Jongejan F, Uilenberg G. The global importance of ticks. Parasitology. 2004;129(Suppl):S3-14.

4. Wikel SK. Ticks and tick-bBorne infections: complex ecology, agents, and host interactions. Vet Sci. 2018;5(2):60.

5. European Centre for Disease Prevention and Control. Ixodes ricinus-current known distribution: January 2018. [cited 2020 Aug 30]. https://www. ecdc.europa.eu/en/publications-data/ixodes-ricinus-current-known-distr ibution-january-2018. Accessed June 2020.

6. Estrada-Peña A, Mihalca AD, Petney TN, editors. Ticks of Europe and North Africa. Cham: Springer International Publishing; 2017.

7. James CA, Pearl DL, Lindsay LR, Peregrine AS, Jardine CM. Risk factors associated with the carriage of Ixodes scapularis relative to other tick species in a population of pet dogs from southeastern Ontario, Canada. Ticks Tick Borne Dis. 2019;10:290-8.

8. Rizzoli A, Silaghi C, Obiegala A, Rudolf I, Hubálek Z, Földvári G, et al. Ixodes ricinus and its transmitted pathogens in urban and peri-urban areas in Europe: new hazards and relevance for public health. Front Public Health. 2014;2:251.

9. Eisen RJ, Eisen L. The blacklegged Tick, Ixodes scapularis: an increasing public health concern. Trends Parasitol. 2018;34:295-309.

10. Mather TN, Fish D, Coughlin RT. Competence of dogs as reservoirs for Lyme disease spirochetes (Borrelia burgdorferi). J Am Vet Med Assoc. 1994;205:186-8.

11. Kröber T, Guerin PM. In vitro feeding assays for hard ticks. Trends Parasitol. 2007;23:445-9.

12. Otranto D. Arthropod-borne pathogens of dogs and cats: from pathways and times of transmission to disease control. Vet Parasitol. 2018;251:68-77.

13. Varloud $\mathrm{M}$, Liebenberg J, Fourie J. Early Babesia canis transmission in dogs within $24 \mathrm{~h}$ and $8 \mathrm{~h}$ of infestation with infected pre-activated male Dermacentor reticulatus ticks. Parasit Vectors. 2018;11:41.

14. Sertour N, Cotté V, Garnier M, Malandrin L, Ferquel E, Choumet V. Infection kinetics and tropism of Borrelia burgdorferi sensu lato in mouse after natural (via ticks) or artificial (needle) infection depends on the bacterial strain. Front Microbiol. 2018;9:1722.

15. Littman MP, Goldstein RE, Labato MA, Lappin MR, Moore GE. ACVIM small animal consensus statement on Lyme disease in dogs: diagnosis, treatment, and prevention. J Vet Intern Med. 2006;20:422-34.

16. King L, Gerber NL, Ostroff SM, et al. Washington, DC: National Academics Press. Washington, D.C.: National Academies Press; 2011. Critical Needs and Gaps in Understanding Prevention, Amelioration, and Resolution 
of Lyme and Other Tick-Borne Diseases: The Short-Term and Long-Term Outcomes: Workshop Report.

17. Andrade JJ, Xu G, Rich SM. A silicone membrane for in vitro feeding of Ixodes scapularis (Ixodida: Ixodidae). J Med Entomol. 2014;51:878-9.

18. Tajeri S, Razmi G, Haghparast A. Establishment of an artificial tick feeding system to study Theileria lestoquardi infection. PLoS ONE. 2016;11:e0169053.

19. González J, Valcárcel F, Aguilar A, Olmeda AS. In vitro feeding of Hyalomma lusitanicum ticks on artificial membranes. Exp Appl Acarol. 2017;72:449-59.

20. Olivieri E, Wijnveld M, Bonga M, Berger L, Manfredi MT, Veronesi F, et al. Transmission of Rickettsia raoultii and Rickettsia massiliae DNA by Dermacentor reticulatus and Rhipicephalus sanguineus (s.l.) ticks during artificial feeding. Parasit Vectors. 2018;11:494.

21. Körner S, Makert GR, Mertens-Scholz K, Henning K, Pfeffer M, Starke A, et al. Uptake and fecal excretion of Coxiella burnetii by Ixodes ricinus and Dermacentor marginatus ticks. Parasit Vectors. 2020;13:75.

22. Fourie JJ, Stanneck D, Luus HG, Beugnet F, Wijnveld M, Jongejan F. Transmission of Ehrlichia canis by Rhipicephalus sanguineus ticks feeding on dogs and on artificial membranes. Vet Parasitol. 2013;197:595-603.

23. Kröber T, Guerin PM. An in vitro feeding assay to test acaricides for control of hard ticks. Pest Manag Sci. 2007;63:17-22.

24. Sangaré AK, Rolain JM, Gaudart J, Weber P, Raoult D. Synergistic activity of antibiotics combined with ivermectin to kill body lice. Int J Antimicrob Agents. 2016:47:217-23.

25. European Medicines Agency. Annex I-summary of product characteristics. https://www.ema.europa.eu/en/documents/productinformation/\% OAvectra-3d-epar-product-information_en.pdf. Accessed 15 Aug 2020.

26. Barbour AG. Isolation and cultivation of Lyme disease spirochetes. Yale J Biol Med. 1984;57:521-5.

27. Fourie JJ, Evans A, Labuschagne M, Crafford D, Madder M, Pollmeier M, et al. Transmission of Anaplasma phagocytophilum (Foggie, 1949) by Ixodes ricinus (Linnaeus, 1758) ticks feeding on dogs and artificial membranes. Parasit Vectors. 2019;12:136.

28. Trentelman JJA, Kleuskens JAGM, van de Crommert J, Schetters TPM. A new method for in vitro feeding of Rhipicephalus australis (formerly Rhipicephalus microp/us) larvae: a valuable tool for tick vaccine development. Parasit Vectors. 2017:10:153.

29. Otranto D, Dantas-Torres F, Fourie JF, Lorusso V, Varloud V, Gradoni L, Drake J, Geurden T, Kaminsky R, Heckeroth AR, Schunack B, Pollmeier M, Beugnet F, Holdsworth P. World Association for the Advancement of Veterinary Parasitology (W.A.A.V.P.) guidelines for studies evaluating the efficacy of parasiticides in reducing the risk of vector-borne pathogen transmission in dogs and cats. Vet Parasitol. 2021;290:109369.

30. Courtney JW, Kostelnik LM, Zeidner NS, Massung RF. Multiplex real-time PCR for detection of Anaplasma phagocytophilum and Borrelia burgdorferi. J Clin Microbiol. 2004:42:3164-8.

31. Beugnet $F$, Halos L, Larsen D, Labuschagné M, Erasmus H, Fourie J. The ability of an oral formulation of afoxolaner to block the transmission of Babesia canis by Dermacentor reticulatus ticks to dogs. Parasit Vectors. 2014;7:283.

32. Krämer F, Hüsken R, Krüdewagen EM, Deuster K, Blagburn B, Straubinger RK, et al. Prevention of transmission of Borrelia burgdorferi sensu lato and Anaplasma phagocytophilum by Ixodes spp. ticks to dogs treated with the Seresto ${ }^{\circledR}$ collar (imidacloprid 10\% + flumethrin 4.5\%). Par Res. 2020;119:299-315.

33. Koci J, Bernard $Q$, Yang X, Pal U. Borrelia burgdorferi surface protein Lmp1 facilitates pathogen dissemination through ticks as studied by an artificial membrane feeding system. Sci Rep. 2018;8:1910.

34. Patrick MG, Thomas K, Pablo G, Stoyan G, Peter-allan D, Pascal S, et al. Chemsensory and behavioural adaptations of ectoparasitic arthropods. Nova Acta Leopold. 2000;229:213-30.
35. Oliver JD, Lynn GE, Burkhardt NY, Price LD, Nelson CM, Kurtti TJ, et al. Infection of immature Ixodes scapularis (Acari: Ixodidae) by membrane feeding. J Med Entomol. 2016;53:409-15.

36. Kiszewski AE, Matuschka FR, Spielman A. Mating strategies and spermiogenesis in ixodid ticks. Annu Rev Entomol. 2001:46:167-82.

37. Wayop IY. In vitro feeding of all stages of Ixodes ricinus ticks. Faculty of Veterinary Medicine, Utrecht: 2013. https://dspace.library.uu.n//handle/ 1874/288235. Accessed Nov 2020.

38. Kocan KM, Goff WL, Stiller D, Claypool PL, Edwards W, Ewing SA, et al. Persistence of Anaplasma marginale (Rickettsiales: Anaplasmataceae) in male Dermacentor andersoni (Acari: Ixodidae) transferred successively from infected to susceptible calves. J Med Entomol. 1992;29:657-68.

39. Bremer WG, Schaefer JJ, Wagner ER, Ewing SA, Rikihisa Y, Needham GR, et al. Transstadial and intrastadial experimental transmission of Ehrlichia canis by male Rhipicephalus sanguineus. Vet Parasitol. 2005;131:95-105.

40. Varloud M, Warin S, Murphy M, Moran C, McGrath C, Szilágyi N. 24 h and $48 \mathrm{~h}$ acaricidal efficacy of a topical administration of dinotefuran-permethrin-pyriproxyfen or permethrin-pyriproxyfen on dogs against weekly infestations of Ixodes ricinus adult ticks. In: V4 parasitological meetingparasites in the Heart of Europe: 2014. https://www.google.com/url?sa= $\mathrm{t} \& \mathrm{rct}=\mathrm{j} \& \mathrm{q}=\& \mathrm{esrc}=\mathrm{s} \&$ source $=$ web\& $\mathrm{cd}=\& \mathrm{cad}=\mathrm{rja} \&$ uact $=8 \& \mathrm{ved}=2 \mathrm{ah} U \mathrm{~K}$ Ewij1PLsipfyAhWBxoUKHR55C3YQFnoECAoQAw\&url=https\%3A\%2F\% 2Fwww.parazitologie.cz\%2Fakce\%2Fdoc\%2Fsbornik\%2F2014\%2520V4\% 2520Parasitological\%2520Meeting.pdf\&usg=AOVVaw0UeSliJxQnBQ9C VfvsUfBI. Accessed Nov 2020

41. Tahir D, Evans A, Meyer L, Jongejan F, Mather M, Choumet V, Blagburn B, Straubinger RK, Varloud M. Acaricidal efficacy of dinotefuran-pyriproxyfen-permethrin (VECTRA ${ }^{\circledR} 3 D$ ) treated dog hair against adult Ixodes scapularis and Ixodes ricinus ticks using an in vitro feeding assay. In: The American Association of Veterinary Parasitologists 65th Annual Meeting. 2020. https://www.aavp.org/aavp-2020-annual-meeting/. Accessed Dec 2020.

42. Varloud M. Acaricidal efficacy of dog's hair collected over 1 month after a topical administration of dinotefuran-permethrin-pyriproxyfen against the deer tick (Ixodes scapularis). In: 63rd Annual meeting of the American Association of Veterinary Parasitologists. 2018. https://www.aavp.org/ aavp-2018-annual-meeting/. Accessed June 2020.

43. White WH, Plummer PR, Kemper CJ, Miller RJ, Davey RB, Kemp DH, et al. An in vitro larval immersion microassay for identifying and characterizing candidate acaricides. J Med Entomol. 2004;41:1034-42.

44. Pfister K, Armstrong R. Systemically and cutaneously distributed ectoparasiticides: a review of the efficacy against ticks and fleas on dogs. Parasit Vectors. 2016;9:436.

45. Clark JM, Symington SB. Advances in the mode of action of pyrethroids. Top Curr Chem. 2012;314:49-72.

46. Piesman J. Dynamics of Borrelia burgdorferi transmission by nymphal Ixodes dammini ticks. J Infect Dis. 1993;167:1082-5.

\section{Publisher's Note}

Springer Nature remains neutral with regard to jurisdictional claims in published maps and institutional affiliations.

Ready to submit your research? Choose BMC and benefit from:

- fast, convenient online submission

- thorough peer review by experienced researchers in your field

- rapid publication on acceptance

- support for research data, including large and complex data types

- gold Open Access which fosters wider collaboration and increased citations

- maximum visibility for your research: over 100M website views per year

At BMC, research is always in progress.

Learn more biomedcentral.com/submissions 